\title{
Prompts to Increase Stair Climbing in Stations: The Effect of Message Complexity
}

\begin{abstract}
Amanda Louise Lewis and Frank F. Eves
Background/Objective: While point-of-choice prompts consistently increase stair climbing, experimental comparisons of message content are rare. Here, the effects of 2 messages differing in complexity about the health outcomes obtainable from stair climbing were compared. Methods: In a UK train station with 2 independent platforms exited by identical 39-step staircases and adjacent escalators, observers recorded travelers ascent method and gender from 8:00 A.M. to 10:00 A.M. on 2 weekdays during February/March $2008(\mathrm{n}=$ $48,697)$. Baseline observations $(2$-weeks) preceded a 3-week poster phase. Two posters $(594 \times 841 \mathrm{~mm})$ that differed in the complexity of the message were positioned at the point-of-choice between ascent methods, with 1 placed on each side of the station simultaneously. Logistic regression analysis was conducted in April 2010. Results: Omnibus analysis contained main effects of the intervention $(\mathrm{OR}=1.07$, $\mathrm{CI}=1.02-1.13$, $P=.01)$ and pedestrian traffic volume $(\mathrm{OR}=5.42, \mathrm{CI}=3.05-9.62, P<.001)$. Similar effects occurred for complex $(\mathrm{OR}=1.10, \mathrm{CI}=1.02-1.18, P=.01)$ and simple messages $(\mathrm{OR}=1.07, \mathrm{CI}=1.01-1.13, P=.02)$ when analyses controlled for the influence of pedestrian traffic volume. There was reduced efficacy for the complex message during busier periods $(\mathrm{OR}=0.36, \mathrm{CI}=0.20-0.66, P=.001)$, whereas the simple message was immune to these effects of traffic volume. Conclusions: Pedestrian traffic flow in stations can influence message effectiveness. Simple messages appear more suitable for busy sites.
\end{abstract}

Keywords: lifestyle physical activity, obesity, built environment, message content, pedestrian traffic

Physical inactivity, a risk for many diseases, is a continuing public health concern. ${ }^{1}$ Current approaches focus on the accumulation of physical activity as part of daily living. ${ }^{2,3}$ Much of the research targeting lifestyle physical activity has adopted a socioecological model that incorporates effects of the physical environment and the social milieu, as well as intraindividual processes such as intention. ${ }^{4,5}$ One effective way to increase lifestyle physical activity is to increase the use of active transport (eg, walking to destinations).5,6 Unlike walking, stair climbing is a physiologically vigorous lifestyle activity, with field estimates of 9.6 Metabolic Equivalents of Tasks (METs) (ie, 9.6 times the energy requirements of the resting state). ${ }^{7}$

While experimental findings show that regular bouts of stair climbing have been associated with improved cholesterol profile, respiratory fitness and weight loss, ${ }^{8-10}$ climbing a single set of stairs is unlikely to result in substantial health gains. Nonetheless, the accumulation of stair climbing throughout the day increases energy expenditure; an $80 \mathrm{~kg}$ man who climbs a standard $3 \mathrm{~m}$ flight of stairs in his own

Lewis is with the Dept of Primary Care Clinical Sciences, The University of Birmingham, Birmingham, West Midlands, United Kingdom. Eves is with the School of Sport and Exercise Sciences, The University of Birmingham, Birmingham, West Midlands, home 10 extra times a day would expend approximately 28 kcals per day, which, if repeated daily for a year, is energy expenditure equivalent to $3 \mathrm{lbs}$ of fat. ${ }^{11}$ Thus, increased regular use of the stairs rather than the mechanized alternative during active transport is one of a number of current public health targets aiming to increase lifestyle physical activity. ${ }^{2,3}$ Like other types of active transport, stair climbing can be influenced by the social environment; the volume of pedestrian traffic at a particular site and time can have major influences on the behavior. ${ }^{12}$

To increase stair climbing, point-of-choice prompts are positioned between the stairs and escalators encouraging pedestrians to take the stairs for their health. Point-ofchoice prompts interrupt habitual choice of the escalator at the point of occurrence and provoke deliberation about the alternatives. ${ }^{13,14}$ These active environmental interventions have proved an effective strategy to increase the accumulation of stair climbing in public access settings. ${ }^{13-23}$ Nonetheless, most messages are freely generated by investigators or focus groups, with limited testing of message content on the target audience. ${ }^{24} \mathrm{~A}$ recent interview study $(n=1200)$, however, suggested that messages outlining specific health outcomes may have superior motivational properties than more general statements. ${ }^{24}$ Here, we test the effects of 2 messages differing in the specificity with which they detailed a possible outcome of stair climbing on the actual behavior, rather than self-reported motivation. 
Five previous formal comparisons of messages differing in content for public access settings report mixed results. Equivalent effects occurred for messages about heart health and weight control ${ }^{15}$ and the addition of the phrase 'Save time' to the message 'Stay healthy' ${ }^{20}$ in shopping malls. Similarly, a heart health sign and one aimed at restricting escalator use had equivalent effects in an airport. ${ }^{25}$ In contrast, addition of the 'Save time' phrase to the 'Stay healthy' message increased stair climbing in a station. ${ }^{20}$ Further, a message about time to exercise accompanied by a culturally sensitive role model had greater effects on African-American users of a station than a generic sign for heart health tested in pilot work. ${ }^{16}$ Finally, a larger aggregated response occurred for a family-oriented message for heart health $(+2.3 \%)$ than one focused on the individual $(+0.9 \%)$ in an airport. ${ }^{18}$ Nonetheless, the family-oriented message preceded the individual sign and the 2 were never statistically compared. Importantly, sequential testing of message content in all these studies does not control for the possible effects of different histories before each intervention; carry over effects from one intervention to another and adaptation to any attempt to increase stair climbing are possible. Further, no study has compared messages with the same theme, a necessary approach to assessing the effects of specificity of the outcome communicated in the message. Therefore, this study simultaneously compared the effects of 2 messages differing in specificity in a train station with matched staircases. Crucially the possibility of an individual being exposed to both messages was negligible at this site due to the operational structure of train arrival. Trains from the same location always arrived at the same platform on a daily basis. We hypothesized that the more specific health outcome message would have greater effects on stair climbing than the more general one.

As noted earlier, socioecological models include effects of physical and social environments. Here, matched staircases in the same station equated potential effects of the physical environment. Concerning the social environment, pedestrian movement within stations influences stair climbing. Unlike shopping malls, pedestrian traffic flow in stations is pulsatile in nature as the disembarking passengers from a particular train try to leave the station simultaneously. For example, an average of $18.9 \%$ on the stairs when 25 passengers left a train rose to $43.0 \%$ when 150 passengers left a train in the same station $(n=82,347) .{ }^{12}$ Thus, pedestrian traffic in stations has major effects on the choice between stairs and escalators; as traffic increases, stair climbing increases. ${ }^{20,21,26,27}$ Here, we quantify the effects of traffic in the station to facilitate comparison between the effects of interventions and the social environment. Importantly, 2 recent studies in stations reported an interaction between pedestrian traffic volume and the intervention such that it was less effective at higher traffic volumes. ${ }^{21,27}$ One parsimonious explanation for effects of pedestrian traffic is time pressure; when the escalator is full, some passengers avoid delay by opting for the stairs. ${ }^{12}$ It is possible, however, that time pressure in commuters may also affect processing of the message itself. When commuters encounter a point-of-choice prompt, exposure to the message is fleeting and occurs as an incidental part of their journey. A commuter seeking the quickest route out of the station may require more mental resources for this task at higher traffic volumes and hence processing of any incidental message could be impeded. Thus, analyses tested for an interaction between message content and pedestrian traffic volume.

\section{Methods}

\section{Intervention Site}

The intervention site was a UK train station with 2 independent platforms exited by identical 39-step staircases and adjacent escalators (height $=6.64 \mathrm{~m}$ ). Each platform received trains from differing locations, which remained the same for both platforms throughout the duration of the study. Thus, regular passengers arrived at the same platform each day and, hence, could only be exposed to both messages if they set off from different locations on different days. This scenario would be a possible, but we suspect uncommon, journey to work. The intervention site was selected as its layout enabled a simultaneous comparison of point-of-choice prompts. Figure 1 illustrates the station layout. Trains stopped opposite the station buildings and passengers walked along the platform to reach the stairs and escalator to exit the station. Pillars supporting the concourse overhead were the only fixed obstacles present at each platform that might impede a pedestrian's view of the posters.

\section{Procedure}

During February and March 2008, 4 observers (interobserver reliability: average kappa $=0.97$, kappa range 0.94-1.00) recorded stair/escalator choices of ascending travelers, coded by gender, as they left each train between 8:00 A.M. and 10:00 A.M., on Tuesday and Thursday each week; coding for gender alone reflected the high levels of pedestrian traffic..$^{20,21,26}$ Specifically, 2 observers were discretely positioned on each platform; 1 observer recorded male and females ascending the stairs and the other recorded males and females ascending the escalator. Travelers constrained in their ability to use the stairs by a physical incapacity, large bags (larger than a briefcase or medium-sized bag) or accompanying children (head below shoulder height of accompanying adult) were not recorded ${ }^{20,21}$ Thus, our sample represented all individuals exiting a station between 8:00 A.M. and 10:00 A.M. who could ascend the stairs and were not encumbered. In a quasi-experimental, interrupted time series design, a 2-week baseline phase was followed by a 3 -week poster phase. Two A1-sized posters $(594 \times 841$ $\mathrm{mm}$ ) were simultaneously tested, 1 on each side of the station. Positioning of the posters on stands meant that the bottom of the text was 2.37 meters above the ground and hence clearly visible to approaching pedestrians. 


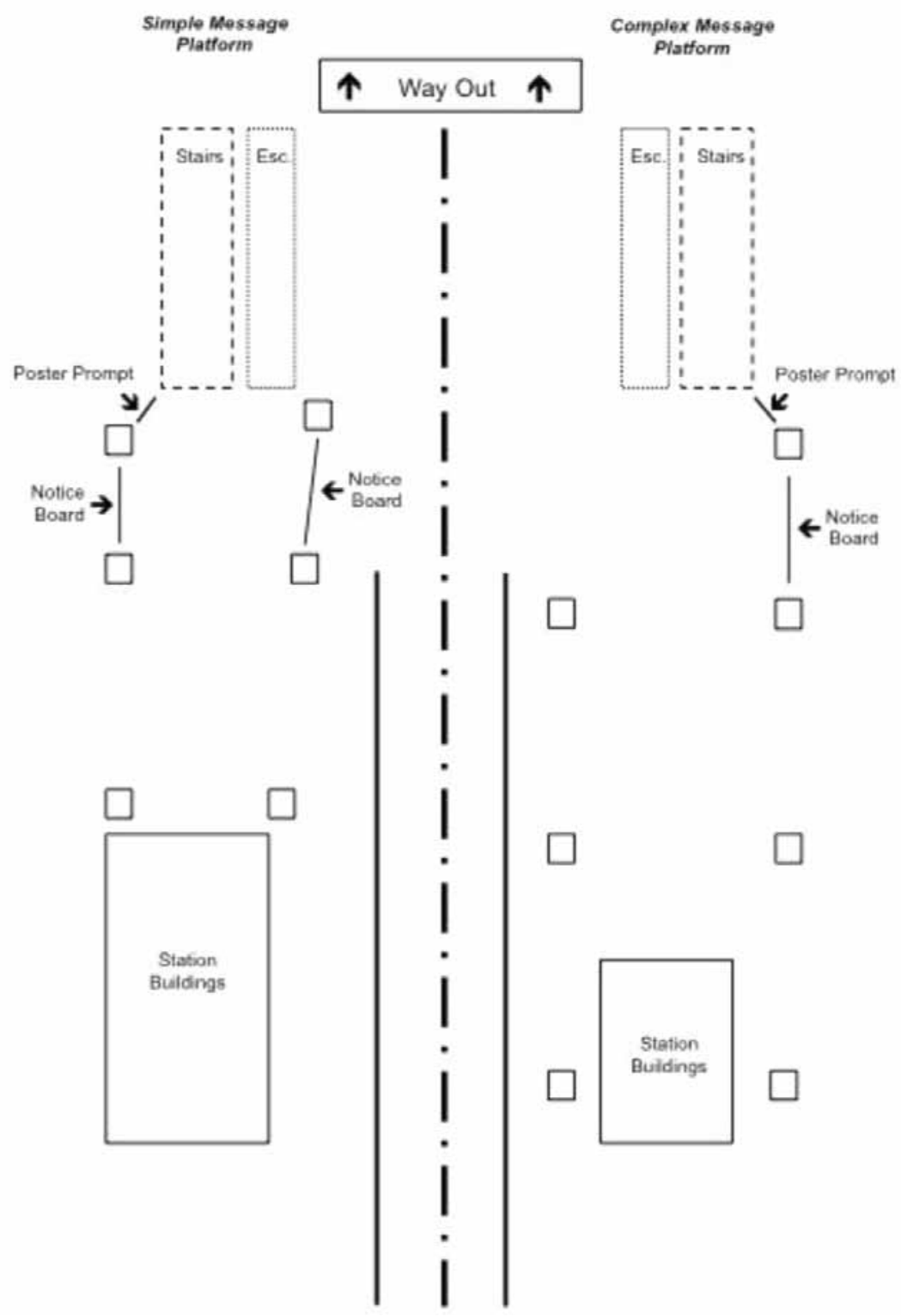

Figure 1 - Schematic of the station floor plan (approximate scale). Trains stopped opposite the station buildings at the bottom of the figure, requiring passengers to walk along the platform to reach the stair and escalator (esc.) complexes depicted at the top of the figure. Train tracks are positioned between the 2 platforms (thick dashed line).

A specific message, 'Regular stair climbing for 7 minutes per day protects your heart,' was compared with the more general message, 'Regular stair climbing protects your heart.' In pilot work, the first message $($ mean = $6.3 \pm 1.9$ ) was rated more specific than the second (mean $\left.=3.9 \pm 1.9 ; t_{39}=4.96 P<.001\right)$ on a 10 -point scale with the anchors not at all (1) and very much (10). It should be noted here that the greater specificity of the first message comes from additional words. The phrase 'for 7 minutes per day' states the amount of stair climbing required to achieve the outcome. The specific message's origin was from a more extended message that aimed to encourage regular stair climbing in a worksite, by incorporating an explicit target for the amount of stair climbing required to achieve health benefits. ${ }^{28}$ Previously, Yu and colleagues estimated that the amount of vigorous exercise required to reduce the risk of heart attack by two-thirds was equivalent to 7 minutes of stair climbing a day. ${ }^{29}$ Focus groups suggested this would be an effective message theme. ${ }^{28}$ The shortened version employed here was previously successful in a UK shopping mall ${ }^{23}$ and, when translated, in a station in Barcelona, Spain. ${ }^{27}$ The additional phrase of the specific message, 'for 7 minutes per day,' increased the length and also the complexity of the message and we refer to it with the term 'complex' in the remainder of the manuscript. As a consequence, the more general message is termed 'simple.' We return to this issue in the discussion. Ethical approval was obtained from the 
ethics subcommittee of the School of Sport and Exercise Sciences, University of Birmingham, Birmingham, UK.

\section{Statistical Analyses}

Logistic regression analysis was conducted in April 2010, with the dichotomous outcome variable of stair/escalator choice and the dichotomous predictors of intervention, message platform and gender. Pedestrian traffic volume (ie, the total number of pedestrians leaving each train) was entered as a continuous variable. Before analysis, this variable was subjected to a natural logarithm transformation and standardized in the range $0-1$ by dividing by the highest value to facilitate comparison with effects for binary variables. ${ }^{26}$ Preliminary inspection revealed higher levels of traffic at the simple message platform $\left(\right.$ mean $=161.6 \pm 87.3$ pedestrians $\cdot$ train $\left.^{-1}\right)$ than the complex one (mean $=130.7 \pm 85.6$ pedestrians $\cdot$ train $^{-1}$; $\left.t_{336}=3.25, P=.001\right)$. To allow assessment of the effects of message platform unconfounded by differences in traffic volume, the data were mean centered for each message platform.

\section{Results}

A total of 48,697 pedestrians were coded $(54.7 \%$ female overall); simple message platform, $\mathrm{n}=23,626,56.7 \%$ female; complex message platform $\mathrm{n}=25,071,52.9 \%$ female). Figure 2 depicts the relationship between pedestrian traffic volume and the percentage climbing stairs overall for the complex and simple message platforms. The fitted lines reflect the natural log of the relationship between the traffic volume and stair climbing. As can be seen, there was a large magnitude effect of pedestrian traffic on stair use at both platforms, with the greater effects at the complex message platform [log slope $=$ 13.1, 95\% Confidence Interval $(\mathrm{CI})=11.9-14.3]$ than

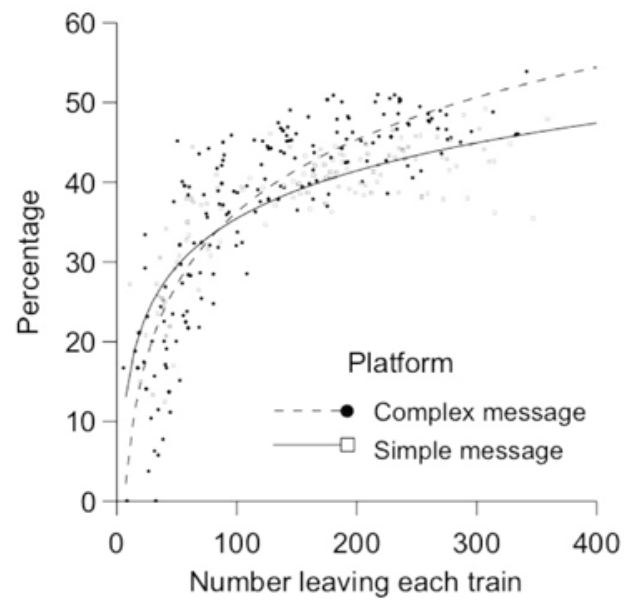

Figure 2 - The overall relationship between pedestrian traffic volume (ie, the number of pedestrians leaving each train) and percentage climbing the stairs at the complex (broken line) and simple message platforms (unbroken line). the simple one $(\log$ slope $=8.6, \mathrm{CI}=7.7-9.5)$ reflected in nonoverlapping confidence intervals.

The omnibus analysis contained main effects of the intervention [Odds Ratio $(\mathrm{OR})=1.07, \mathrm{CI}=1.02-1.13$, $P=.01]$ and pedestrian traffic volume $(\mathrm{OR}=5.42, \mathrm{CI}=$ $3.05-9.62, P<.001)$. While there was no differential effect of the intervention between the message platforms $(\mathrm{OR}=1.04, \mathrm{CI}=0.94-1.14, P=.46)$, a main effect of message platform $(\mathrm{OR}=0.68, \mathrm{CI}=0.80-0.93$, $P<.001)$ interacted with pedestrian traffic $(\mathrm{OR}=6.51$, $\mathrm{CI}=3.26-12.97, P<.001)$ and there was a 3 -way interaction involving message platform, the intervention and pedestrian traffic volume $(\mathrm{OR}=0.29, \mathrm{CI}=0.13-0.64$, $P=.002$ ).

Initial follow-up analyses for each message platform without including an interaction between the intervention and pedestrian traffic, revealed an effect of the intervention at the simple message platform (baseline stairs $=39.5 \%$, intervention stair $=41.4 \%$ : OR $=1.07$, $\mathrm{CI}=1.01-1.13, P=.02)$. In contrast, the analysis for the more complex message platform suggested no effect (baseline stairs $=41.9 \%$, intervention stair $=42.4 \%$ : OR $=0.99, \mathrm{CI}=0.94-1.04, P=.63$ ) when the analysis did not include the possible interaction between intervention and pedestrian traffic. Importantly, however, the effects of standardized traffic were large at both platforms (Simple $\mathrm{OR}=6.95, \mathrm{CI}=4.97-9.71 ;$ Complex $\mathrm{OR}=18.75, \mathrm{CI}=$ 14.19-24.78). The smaller effects of standardized traffic at the simple message platform reflect higher average pedestrian traffic levels at this platform $(161.6 \pm 87.3$ pedestrians.train $\left.{ }^{-1}\right)$ than the complex message one (130.7 \pm 85.6 pedestrians $\left.\cdot \operatorname{train}^{-1}\right)$. Effects of pedestrian traffic plateau at levels around 150-200 (see Figure 2) as the stairs become saturated with pedestrians $\left(\mathrm{see}^{12}\right)$. Hence, the effects of pedestrian traffic will be reduced when overall traffic is high (ie, the simple message platform).

Figure 3 depicts the relationship between percentage stair climbing and the natural log of pedestrian traffic during the baseline and intervention periods at each platform. Inclusion of the interaction of the intervention with pedestrian traffic revealed that pedestrian traffic influenced intervention effectiveness for the complex message $(\mathrm{OR}=0.36, \mathrm{CI}=0.20-0.66, P=.001)$. As can be seen from Figure $3 b$ effects of the intervention were reduced at higher traffic volumes (ie, busier periods). In contrast, there was no interaction between pedestrian traffic and the intervention for the simple message (OR $=1.48, \mathrm{CI}=0.72-3.02, P=.28)$ and this interaction term was removed for the final models for each platform summarized in Table 1. As can be seen, similar effects for the 2 messages were apparent when effects of pedestrian traffic were controlled. In addition, males chose the stairs more than females at the simple message platform but not the complex message one. Follow-up analyses revealed no significant changes in the effects of the intervention over successive weeks for either the simple message $(\mathrm{OR}=0.97, \mathrm{CI}=0.93-1.02, P=.25)$ or the more complex one $(\mathrm{OR}=1.00, \mathrm{CI}=0.94-1.06$, $P=.99)$. 
$3 \mathrm{a}$

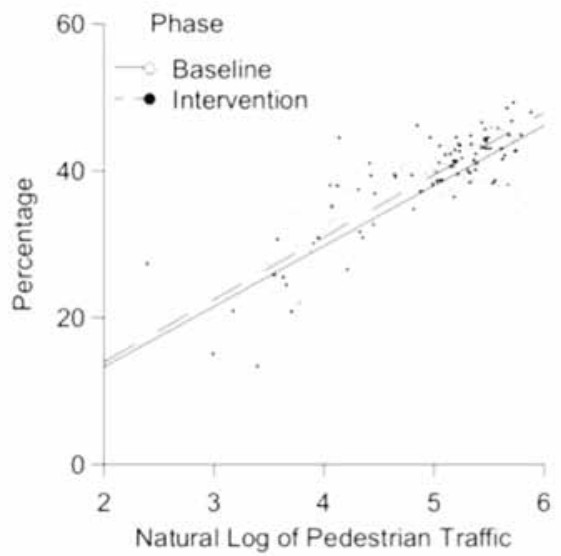

$3 b$

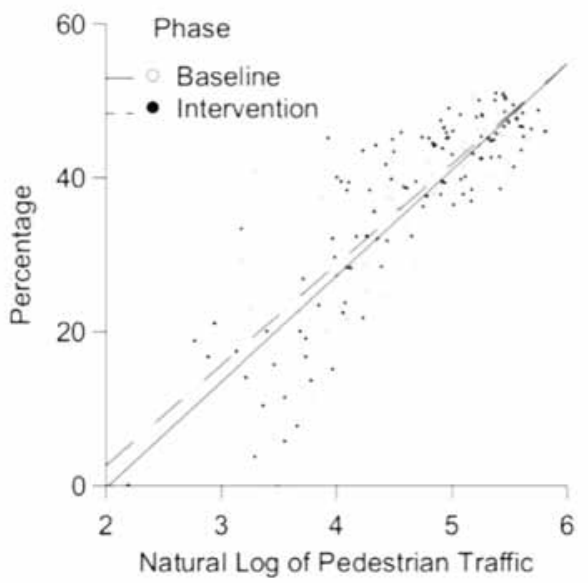

Figure 3 - Effects of pedestrian traffic volume on percentage climbing the stairs during the baseline and intervention for the simple message (3a) and complex message platforms (3b).

Table 1 Odds Ratios and Confidence Intervals for Stair Climbing, According to Message Type, at a UK Train Station ( $N=48,697,54.7 \%$ Female Overall; Data Collected February/March 2008)

\begin{tabular}{|c|c|c|c|c|}
\hline & \multicolumn{2}{|c|}{$\begin{array}{c}\text { Complex message } \\
\mathrm{n}=\mathbf{2 5 , 0 7 1}(\mathbf{5 2 . 9} \% \text { female })\end{array}$} & \multicolumn{2}{|c|}{$\begin{array}{c}\text { Simple message } \\
\mathrm{n}=23,626(56.7 \% \text { female })\end{array}$} \\
\hline & OR & $95 \% \mathrm{Cl}$ & OR & $95 \% \mathrm{Cl}$ \\
\hline Intervention (intervention $>$ baseline) & $1.10 *$ & $1.02-1.18$ & $1.07 *$ & $1.01-1.13$ \\
\hline Gender (male > female) & 0.99 & $0.94-1.04$ & $1.29 * * *$ & $1.23-1.36$ \\
\hline Pedestrian traffic volume & $39.05 * * *$ & $23.7-64.4$ & $6.95 * * *$ & $4.97-9.71$ \\
\hline Pedestrian traffic volume $\times$ intervention & $0.36^{*}$ & $0.20-0.66$ & $\mathrm{n} / \mathrm{a}$ & $\mathrm{n} / \mathrm{a}$ \\
\hline
\end{tabular}

$* P<.05 ; * * * P<.001$.

\section{Discussion}

This study compared the effects of 2 messages differing in complexity brought about by the greater specificity of one of the messages. Similar effects on stair climbing were evident for the more specific, but also more complex, health outcome message and a simpler one, when the effects of pedestrian traffic were controlled. Thus, direct auditing of the target behavior in the context of a station does not confirm self-reports that specific outcome messages would be more motivating than general messages. ${ }^{24}$ While effects of the intervention were small, effects of pedestrian traffic were large and the interaction between traffic volume and the intervention for the more complex message indicates its effects were diluted during busier periods.

Similar reductions in the efficacy of prompts detailing specific outcomes at higher traffic volumes have been observed previously in train stations in the $\mathrm{UK}^{21}$ and Spain, ${ }^{27}$ attesting to the robustness of this effect. In contrast, analysis of a recent study in a subway station in Glasgow, Scotland contained no interaction between pedestrian traffic and the intervention message 'Stay healthy, save time, use the stairs.' ${ }^{30}$ Concerning differences between the messages, the more complex message here contained the additional phrase 'for 7 minutes per day.' This addition not only increased the specificity of the outcome but also the length and the complexity of the message. Both of these increases would have required more processing resources. A longer message would take longer to read whereas time pressure to leave the station may have impeded adequate deliberation about a more complex message. Preoccupation with finding the quickest route out of the station could only exacerbate these effects. Concerning message length, the 6-word, simple message here and one of the same length in Glasgow, ${ }^{30}$ were not associated with an interaction between traffic and the intervention. In contrast, the specific, and hence more complex, message here contained 11 words, with the 2 previous studies with interactions between the intervention and pedestrian traffic using 12-word ${ }^{21}$ and 10-word ${ }^{27}$ messages, respectively. While the data here cannot distinguish effects of complexity from length, per se, when taken together the results suggest that simpler messages may be more suitable for busy public access sites. In the different behavioral contexts provided by worksites or 
shopping malls, however, processing and elaboration of a more specific and hence complex message may not be impeded by either pedestrian traffic or time pressure.

Although it is common to aggregate data from studies in meta-analyses, a note of caution is appropriate; raw data are uncorrected for the influence of other, relevant variables. Effects of pedestrian traffic volume on stair climbing are almost ubiquitous. In shopping malls, increased traffic is also associated with increased stair climbing ${ }^{31}$ though the pulsatile nature of traffic results in greater absolute effects in train stations. ${ }^{12}$ For worksites where the choice is between stairs and an elevator, the 'business' of the building (ie, its occupancy) can reduce the availability of the elevator to incoming pedestrians. ${ }^{32}$ As a result, crude traffic measures (ie, over 15-minute periods) show similar positive relationships between stair climbing and pedestrian traffic (Lewis and Eves, submitted). When pedestrian traffic is measured every minute, however, the relationship with stair use in buildings is negative; increased traffic is associated with reduced stair climbing..$^{32}$ To illustrate the importance of pedestrian traffic, Figure 4 depicts the overall percentage stair climbing (ie, averaged across platforms, plotted against the natural logarithm of traffic during baseline and interventions periods). The preponderance of high traffic values at the simple message platform when the intervention was effective partially compensates for the ineffectiveness of the complex message at the same traffic level. What Figure 4 illustrates is an effect of the intervention superimposed on a large magnitude effect of pedestrian traffic. These effects of pedestrian traffic represent uncontrolled sources of variation in stair climbing. Inclusion of traffic in analyses aims to avoid effects of contextual variables that could change independently of the intervention. The point here is that any meta-analysis that uses raw data and, hence does not include the effects of traffic, risks misleading researchers and being less informative than the primary research allows $\left(\mathrm{see}^{31}\right)$.

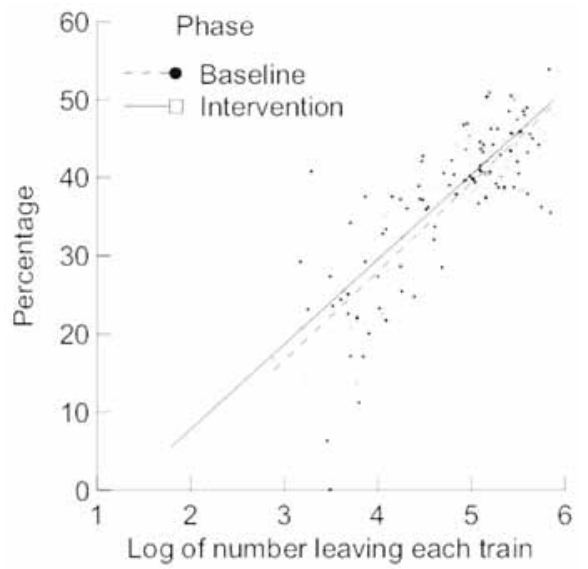

Figure 4 - The overall relationship between pedestrian traffic volume (ie, the number of pedestrians leaving each train) and percentage climbing the stairs during the baseline (broken line) and intervention periods (unbroken line).

\section{Limitations and Future Directions}

The absence of a nonintervention control site is a limitation. Nonetheless, the simultaneous comparison of differing messages and their differing effects, reduces the plausibility of any explanation for responses to the intervention based on uncontrolled factors. In this station, trains from the same locations arrived at the same platform on a daily basis and the risk of passengers seeing both intervention messages and hence, intervention contamination was minimized. Importantly, a major potential confound, pedestrian traffic volume, was controlled in analyses. Further, direct auditing of the target behavior with excellent interobserver reliability (average kappa $=$ 0.97 ) provides stronger evidence than self-reports in the previous study. ${ }^{24}$ While the moderation of the effects of message by pedestrian traffic is informative, some caution is appropriate; the results could be station-specific. Males chose the stairs more than females at the general message platform in stations as expected. ${ }^{20,21,26,27}$ Hence, the absence of gender differences at the complex message platform appears anomalous but has been reported previously. ${ }^{16}$ Set against a station specific explanation, many stations, especially during the rush to work, have pedestrian traffic flows that are pulsatile in nature. Thus, the key factor may not be traffic volume per se but rather traffic type. The fact that similar interactions between pedestrian traffic and a point-of-choice intervention occur elsewhere suggests the moderating effects of traffic volume will generalize to other station settings. In shopping malls, however, traffic flows are more evenly distributed over time. As a result, response to a more complex message may not be affected by pedestrian traffic in such a setting.

In any observational study, coding is extremely important. While we were able to code gender, the high levels of pedestrian traffic coupled with the pulsatile nature of traffic flow, meant that with only 4 coders (ie, 2 per platform) we were unable to code additional demographic information. Age, ethnicity and encumbrances such as large bags or accompanying children, can all influence stair/escalator choice $\left(\mathrm{cf}^{20,21}\right)$. More coders would be required if future studies wished to assess the effects of messages on different population subgroups. Furthermore, our observations were limited to 2 weekdays per week, between 8:00 A.M. and 10:00 A.M. Future research that included different days and times would describe more completely the effects of these interventions. Finally, this short-term study set-out to formally compare the effects of 2 messages differing in content in a setting that minimized alternative explanations of any differing efficacy. There were no changes in efficacy of either message over the 3-week period as reported previously for a poster. ${ }^{21}$ Only longer term studies, however, with subsequent removal of the message, could address issues of maintenance of the effects.

\section{Conclusion}

Prompted increases in stair climbing is one of a range of approaches to the problem of physical inactivity. 
While messages detailing more specific outcomes of stair climbing can be effective in public access settings, health promoters should note that processing of complex or long messages may be impaired at busy sites. Further, effects of pedestrian traffic were of large magnitude and should be controlled in analyses.

\section{Acknowledgments}

We thank Ceri Jones, Rachel Kemp, John Ali and Richard Fiddy for helping with data collection and West Midlands Travel for their permission to use the local train stations.

\section{References}

1. World Health Organization. The World Health Report 2002_reducing risks, promoting healthy life. Switzerland; 2002.

2. Department of Health. Choosing activity: a physical activity action plan. London: Department of Health Publications; 2005.

3. U.S. Department of Health and Human Services. Small steps: take small steps today! U.S. http://www.smallstep. gov/sm_steps/sm_steps_index.html. Accessed $20^{\text {th }}$ May 2010.

4. Giles-Corti B, Donovan RJ. Increasing walking: the relative influence of individual, social environmental and physical environmental factors. Am J Public Health. 2003;93:1583-1589. PubMed doi:10.2105/ AJPH.93.9.1583

5. Sallis JF, Bauman A, Pratt M. Environmental and policy interventions to promote physical activity. Am J Prev Med. 1998;15:379-397. PubMed doi:10.1016/S07493797(98)00076-2

6. Frank LD, Sallis JF, Conway TL, Chapman JE, Saelens BE, Bachman W. Many pathways from land use to health. J Am Plann Assoc. 2006;72:75-86. doi:10.1080/01944360608976725

7. Teh KC, Aziz AR. Heart rate, oxygen uptake, and energy cost of ascending and descending the stairs. Med Sci Sports Exerc. 2002;34:695-699. PubMed doi:10.1097/00005768200204000-00021

8. Boreham CAG, Kennedy RA, Murphy MH, Tully M, Wallace WFM, Young I. Training effects of shout bouts of stair climbing on cardiorespiratory fitness, blood lipids, and homocysteine in sedentary young women. $\mathrm{Br}$ J Sports Med. 2005;39:590-593. PubMed doi:10.1136/ bjsm.2002.001131

9. Kennedy RA, Boreham CA, Murphy MH, Young IS, Mutrie N. Evaluating the effects of a low volume stairclimbing programme on measures of health-related fitness in sedentary office workers. J Sports Sci Med. 2007;6:448-454.

10. Meyer P, Kayser B, Kossovsky MP, et al. Stairs instead of escalators at workplace: cardioprotective effects of a pragmatic intervention. Eur J Cardiovasc Prev Rehabil. 2010;17:569-575. PubMed doi:10.1097/ HJR.0b013e328338a4dd

11. Olander EK, Eves FF. Effectiveness and cost of two stairclimbing interventions-less is more. Am J Health Promot. 2011;25:231-236. PubMed doi:10.4278/ajhp.090325QUAN-119

12. Eves FF, Lewis AL, Griffin C. Modelling effects of stair width on rates of stair climbing in a train station.
Prev Med. 2008;47:270-272. PubMed doi:10.1016/j. ypmed.2007.12.008

13. Kerr J, Eves F, Carroll D. Six-month observational study of prompted stair climbing. Prev Med. 2001;33:422-427. PubMed doi:10.1006/pmed.2001.0908

14. Webb OJ, Eves FF. Promoting stair climbing: intervention effects generalize to a subsequent stair ascent. Am J Health Promot. 2007;22:114-119. PubMed doi:10.4278/08901171-22.2.114

15. Andersen RE, Franckowiak SC, Snyder J, Barlett SJ, Fontaine KR. Can inexpensive signs encourage the use of stairs? Results from a community intervention. Ann Intern Med. 1998;129:363-369. PubMed

16. Andersen RE, Franckowiak SC, Zuzak KB, Cummings ES, Barlett SJ, Crespo CJ. Effects of a culturally sensitive sign on the use of stairs in African American commuters. Soz Praventivmed. 2006;51:373-380. PubMed doi:10.1007/ s00038-006-5095-5

17. Brownell KD, Stunkard AJ, Albaum JM. Evaluation and modification of exercise patterns in the natural environment. Am J Psychiatry. 1980;137:1540-1545. PubMed

18. Coleman KJ, Gonzalez EC. Promoting stair use in a US-Mexico border community. Am J Public Health. 2001;91:20072009. PubMed doi:10.2105/AJPH.91.12.2007

19. Eves FF. Effects of point-of-decision prompts for stair use depend on the alternative. Am J Prev Med. 2010;38:573574. PubMed doi:10.1016/j.amepre.2010.02.004

20. Kerr J, Eves FF, Carroll D. The influence of poster prompts on stair use: the effects of setting, poster size and content. Br J Health Psychol. 2001;6:397-405. PubMed doi:10.1348/135910701169296

21. Olander EK, Eves FF, Puig-Ribera A. Promoting stair climbing: stair-riser banners are better than posters... sometimes. Prev Med. 2008;46:308-310. PubMed doi:10.1016/j.ypmed.2007.11.009

22. Soler RE, Leeks KD, Buchanan LR, et al. Point-ofdecision prompts to increase stair use. Am J Prev Med. 2010;38:S292-S300. PubMed doi:10.1016/j. amepre.2009.10.028

23. Webb OJ, Eves FF. Effects of environmental changes in a stair climbing intervention: generalization to stair descent. Am J Health Promot. 2007;22:38-44. PubMed doi:10.4278/0890-1171-22.1.38

24. Webb OJ, Eves FF. Promoting stair climbing: effects of message specificity and validation. Health Educ Res. 2007;22:49-57. PubMed doi:10.1093/her/cyl045

25. Russell WD, Hutchinson J. Comparison of health promotion and deterrent prompts in increasing use of stairs over escalators. Percept Mot Skills. 2000;91:55-61. PubMed

26. Eves FF, Olander EK, Nicoll G, Puig-Ribera A, Griffin C. Increasing stair climbing in a train station: the effects of contextual variables and visibility. J Environ Psychol. 2009;29:300-303. doi:10.1016/j.jenvp.2008.10.002

27. Puig-Ribera A, Eves FF. Promoting stair climbing in Barcelona: similarities and differences with interventions in English-speaking populations. E J Pub Health. 2010;20:100-102. PubMed doi:10.1093/eurpub/ckp059

28. Eves FF, Webb OJ, Mutrie N. A workplace intervention to promote stair climbing: greater effects in the overweight. Obesity (Silver Spring). 2006;14:2210-2216. PubMed doi:10.1038/oby.2006.259

29. Yu S, Yarnell JW, Sweetnam PM, Murray L. What level of physical activity protects against premature cardiovascular death? The Caerphilly study. Heart. 2003;89:502-506. PubMed doi:10.1136/heart.89.5.502 
30. Ryan J, Lyon K, Webb OJ, Eves FF, Ryan CG. Promoting physical activity in a low socioeconomic area: results from an intervention targeting stair climbing. Prev Med. 2011;52:352-354. PubMed doi:10.1016/j. ypmed.2011.03.004
31. Webb OJ, Eves FF, Kerr J. A statistical summary of mallbased stair climbing interventions. J Phys Act Health. 2011;8(4):558-65. PubMed

32. Olander EK, Eves FF. Elevator availability and its impact on stair use in a workplace. J Environ Psychol. 2011;31:200-206. doi:10.1016/j.jenvp.2011.03.001 